\title{
Cost effectiveness of interventions to improve
} adherence to statin therapy in ASCVD patients in the United States

\author{
Shannon O Armstrong' \\ Richard A Little 2,3 \\ 'The Medicines Company, Health \\ Economics and Outcomes Research, \\ Parsippany, NJ, USA; ${ }^{2}$ Consultant Health \\ Economist, Cambridge, UK; ${ }^{3}$ London \\ School of Hygiene and Tropical \\ Medicines, London, UK
}

This article was published in the following Dove Press journal: Patient Preference and Adherence

\begin{abstract}
Introduction: Cardiovascular disease (CVD) is the leading cause of death in the United States, and high cholesterol is a leading risk factor for CVD. While statins are effective at reducing cholesterol, they are frequently underused in patients at highest risk of CVD. The objective of this study was to identify interventions which may improve adherence to statins and to assess their cost effectiveness within the US Medicare population.

Methods: A literature review was undertaken to identify interventions to improve adherence in patients with CVD at highest risk of a recurrent event and to quantify non-adherence and the consequences of non-adherence to statins in this population. A Markov cost-utility model was developed to assess the cost effectiveness of these interventions.

Results: Ten adherence interventions were identified in the literature, with 6 demonstrating statistically significant improvement in adherence. The six interventions were disease management, interactive voice response, nurse counselling, discharge letter, nurse/dietician counselling and electronic pill bottle with feedback. The model found the cost effectiveness of an intervention was highly dependent on its effectiveness and costs. Incremental cost effectiveness ratios ranged from \$27,545/QALY for discharge letter with large adherence gain to $\$ 130,399 /$ QALY for disease management program with small adherence gain.

Conclusion: Some interventions to improve adherence have been shown to be effective, but little attention has been paid to the costs. Further studies on adherence interventions should include economic evaluations.
\end{abstract}

Keywords: cost-effectiveness, adherence, statins, cardiovascular disease

\section{Introduction}

Cardiovascular disease (CVD) is the leading cause of death in the United States (US) and is estimated to cost the US more than $\$ 1$ trillion a year by $2035 .{ }^{1}$ High cholesterol is a leading risk factor for CVD. ${ }^{2,3} \mathrm{HMG}-\mathrm{CoA}$ reductase inhibitors (statins) have been shown to be a highly effective treatment to lower low-density lipoprotein cholesterol (LDL-C) and the risk of CVD across a wide spectrum of patient types. ${ }^{4}$ Now mostly available as inexpensive generic drugs, statins represent an opportunity to reduce CVD at a low cost. ${ }^{5}$ Despite evidence supporting the use of these medications, their effectiveness is limited by non-adherence (either not taking or not consistently taking) with more than half $(59.1 \%)$ of the eligible population not currently taking statins. ${ }^{3}$

Lin and colleagues reported on persistence to statin therapy over 5 years in patients at highest risk of CVD and found $53 \%$ of patients discontinued therapy
Correspondence: Shannon O Armstrong The Medicines Company, Health Economics and Outcomes Research, 8 Sylvan Way, Parsippany, NJ, USA $\mathrm{Tel}+$ I 6175848869

Email Shannon.armstrong@themedco.com 
with a median time to discontinuation of 15 months. ${ }^{6}$ In a separate study of the secondary prevention population only $44 \%$ were still consistently taking statin medication 6-12 months post myocardial infarction. ${ }^{7}$ Multiple studies assessing compliance with statin treatment in high risk patients have found only $50-61.7 \%$ of patients are compliant with statin therapy after 1 year, ${ }^{8,9}$ although some patients will eventually resume therapy. ${ }^{10}$ The effect of non-adherence may be substantial, as studies assessing the clinical impact of non-compliance and non-persistence have found an unequivocal increased risk of CVD events and mortality. ${ }^{11-21}$

While scattered efforts have been made to identify and pilot interventions to improve adherence to statins, no solution has been widely implemented. The objective of this analysis is to identify successful adherence support interventions for the secondary prevention of atherosclerotic cardiovascular disease (ASCVD) that are likely to be cost effective within the US healthcare system.

\section{Methods}

A review of the literature describing statin adherence interventions and their impact was conducted, and their efficacy and costs evaluated using a Markov cost-utility model taking the perspective of US Medicare.

\section{Literature review}

A structured literature review was undertaken to identify interventions and data to populate the model. The research question was: "What interventions have been shown to improve adherence to statin therapy in patients with established CVD and what has been the impact on outcomes?"

The search focused on the areas of statins, adherence, compliance and persistence. Full details of the search strategy can be found in Table S1. English-language articles were searched for the time period 1 January 2007 to 31 December 2016. This time period reflects a period when statin use was well established for managing hypercholesterolemia in the secondary prevention population and while many branded statin agents were becoming available as low cost generics, which has encouraged research into increasing their use.

The PICO framework was used to evaluate studies for inclusion in the final review. Inclusion and exclusion criteria is shown in Table S2. Effectiveness of an intervention was defined as a statistically significant improvement in adherence.

\section{Economic model}

A Markov model was developed in Microsoft Excel to evaluate the impact of improving adherence to statins on healthcare costs and quality-adjusted life years (QALYs). The comparator was the current standard of care, prescription of a statin without any effort to support adherence, and reported real world adherence rates. The model took the perspective of the national Medicare program, used a cycle length of 1 year and was run for 30 years. ${ }^{22}$

\section{Model structure}

The model was developed to simulate the course of disease in a cohort of 1,000 patients with CVD. For the base case analysis the cohort assumed the mean age and gender distribution of non-fatal myocardial infarction patients without complications taken from the National Inpatient Sample of the Healthcare Cost and Utilization Project (67 years old, $55 \%$ male). ${ }^{23}$

A baseline risk of second CVD event (cardiac arrest, myocardial infarction, unstable angina, stroke, coronary revascularization procedure, and CVD and non-CVD death) was developed based on the literature for risk of events in patients with CVD. ${ }^{24-27}$

Patients were assumed to receive a statin prescription at discharge following ASCVD event and began the model in 1 of 3 medication taking states: compliant $(\geq 80 \%$ taking of medication), non-compliant ( $>0 \%$, but $<80 \%$ ) or nonpersistent (not on statin therapy). A patient's current and historical medication taking status determined the risk of a second CVD event.

Relative risk of experiencing a second event while on statin therapy was based on a meta-analysis of statin trials from the Cholesterol Treatment Trialists Collaboration which found that statins provided a small benefit in the first year which increased with time on therapy. Therefore, differential risk reductions were applied depending on how long a patient had been on statin therapy. Patients who discontinued statin therapy and reinitiated were assumed to receive the smaller first year benefit, with the benefit increasing with time spent on therapy.

Within each cycle, patients could change their medication taking behavior, for example becoming compliant after being non-persistent, or experience a CVD event or death. While adherence could worsen over time, it was assumed that only an event, either a CVD event or a visit to the doctor, could trigger an improvement in compliance, based on literature indicating that some patients resume 
therapy after an event. ${ }^{9,10}$ Patients re-initating therapy after non-persistence were assumed to be compliant in the first year after re-initiating. Patients were assumed to maintain their level of adherence at 3 years after initiating statins, based on literature showing that adherence levels begin to stabilize after several years of medication taking. ${ }^{6}$

Following a second event, patients entered a new state which was a combination of medication taking behaviour, time on medication (years 1,2,2+) and event sequelae. In total, the model included 16 health states.

Figure 1 depicts the decision tree for the first cycle of the model for compliant patients and a Markov diagram of the health states and the possible movement between them. In order to simplify the schematic, the annual transitions (ie, compliant year 1 to compliant year 2) have not been depicted. The decision tree itself is identical for intervention and comparator, with only the probabilities of compliance and persistence differing.

\section{Intervention}

The intervention is a program to improve statin adherence, beginning at receipt of initial statin prescription at hospital discharge. While the period of the interventions reported was 1 year or less, the model assumed the intervention continued for patient's lifetime. Since statin adherence in the control groups of the interventions studied varied and was often higher than what has been reported for real world populations, the improvement in adherence was modelled using relative improvement. Relative improvement was calculated by dividing adherence in the intervention group by adherence in the control group.
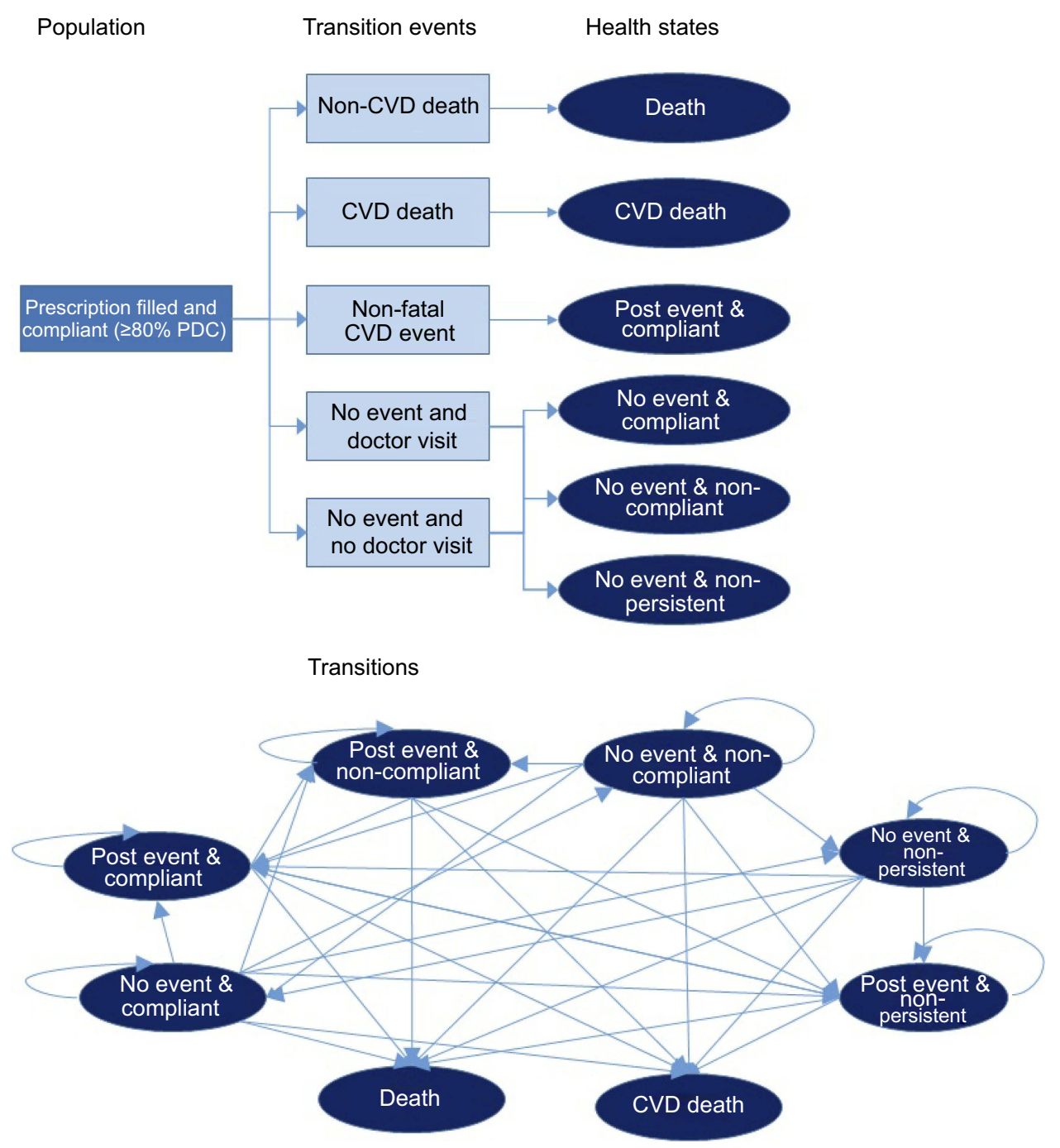

Figure I Model schematics of decision tree and Markov transitions. 


\section{Clinical inputs}

Clinical inputs were taken from the medical literature on adherence. The impact of statin taking on CVD events was taken from a meta-analysis of statin clinical trials. ${ }^{4}$ Relative risks, drawn from the literature review, were applied to account for the increased risk of events associated with noncompliance and non-persistence. ${ }^{15,19,28,30}$ Table 1 shows model inputs. Age and gender specific United States mortality data were taken from the National Vital Statistics Report from the US Centers for Disease Control and Prevention for the calendar year 2012, the most recent data available. ${ }^{29}$

\section{Health state utilities}

Health state utilities were used to calculate QALYs. Health state utilities are based on a range from 0 to 1 , where 0 equals death and 1 equals perfect health. Utilities were taken from studies assessing preference-based EQ-5D scores for chronic health conditions in the United States. ${ }^{31-33}$ Baseline utility was decremented for each year of age as described in the literature. $^{31}$

\section{Cost inputs}

The costs for acute events were taken from published charges for inpatient care from the National Inpatient Sample of the Healthcare Cost and Utilization Project calendar year 2014, the most recent data available. ${ }^{34}$

Costs for the adherence interventions were taken from the studies where cost information was provided. Otherwise, costs were estimated from a study of adherence intervention costs by Chapman and colleagues. ${ }^{35}$ Outpatient costs, drug costs and health state costs were drawn from published sources. ${ }^{36-38}$ Cost inputs are shown in Table 2. When studies reported total counselling time for interventions, this was used in combination with time cost report by Chapman et al to estimate an intervention's costs. Any costs from countries other than the United States were converted to US dollars using purchasing power parity conversion from University College London at https://eppi.ioe.ac.uk/costconversion/. All costs are reported in 2016 US dollars.

Future costs and outcomes were discounted at 3.0\% per annum, following recommended practice in the US. ${ }^{39}$ Incremental cost effectiveness ratios (ICER) were developed by comparing the costs and effects of each adherence intervention against prescription of a statin without any effort to support adherence and reported real world adherence rates.

\section{Sensitivity analysis}

To assess the impact of parameter uncertainty on results, one-way and probabilistic sensitivity analyses were undertaken.

Probabilistic sensitivity analysis used a Monte Carlo approach to generate 5,000 simulations of the model for each intervention with statistically significant improvement in adherence. Inputs were varied within 95\% confidence intervals (CI) where available, or by ranges identified in the literature where CIs were not available. If neither confidence intervals nor ranges were available, a $\pm 20 \%$ variation was used.

\section{Results}

\section{Literature review}

A total of 1,129 papers were identified. After removing duplicates and reviewing titles and abstracts, 11 manuscripts covering 10 interventions were identified. Figure 2 depicts the PRISMA flow diagram.

Interventions evaluated included disease management, ${ }^{40}$ follow-up counselling, ${ }^{41-45}$ reminders messages, ${ }^{46-48}$ and information at discharge (Table 3). ${ }^{49,50}$

Following review of the literature, 6 interventions were identified as effective adherence methods to use in the economic model. These were: disease management, ${ }^{40}$ nurse counseling, ${ }^{43}$ discharge letter, ${ }^{49,50}$ nurse/dietician counseling, ${ }^{45}$ electronic pill bottle ${ }^{47}$ and interactive voice response. $^{48}$

\section{Economic results}

Of the interventions that demonstrated effectiveness, costs varied. The detailed discharge letter described was estimated to cost $\$ 44.95$ once, while the nurse counselling program was estimated to cost $\$ 745.37$ per patient per year (Table 4). Four interventions, Discharge Letter, Nurse/dietician counselling, Electronic Pill Bottle and IVR+, had ICERs which fell below the $\$ 50,000$ per QALY threshold. ICERs for Disease Management and Nurse Counselling were estimated to be $>\$ 100,000$ per QALY.

\section{Sensitivity analyses}

One-way sensitivity analysis assessed the impact of individual parameters on model results with the full range of costs and effectiveness of all interventions included; the resultant tornado diagram of all inputs with a greater than $0.1 \%$ influence on results is shown in Figure 3. This sensitivity analysis found inputs related to intervention effectiveness and cost to have the 
Table I Clinical inputs

\begin{tabular}{|c|c|c|c|c|}
\hline Variable & Value & $\begin{array}{l}\text { Confidence interval or range for sensi- } \\
\text { tivity analysis }\end{array}$ & $\begin{array}{l}\text { Distribution for sensitivity } \\
\text { analysis }\end{array}$ & Source \\
\hline \multicolumn{4}{|l|}{ Statin Treatment } & \\
\hline Relative risk of coronary event year I & 0.86 & $0.77-0.95$ & Lognormal & 4 \\
\hline Relative risk of revascularization year I & 0.95 & $0.84-1.08$ & Lognormal & 4 \\
\hline Relative risk of stroke year I & 0.96 & $0.79-1.17$ & Lognormal & 4 \\
\hline Relative risk of coronary event year 2 & 0.78 & $0.70-0.87$ & Lognormal & 4 \\
\hline Relative risk of revascularization year 2 & 0.76 & $0.66-0.87$ & Lognormal & 4 \\
\hline Relative risk of stroke year 2 & 0.75 & $0.62-0.90$ & Lognormal & 4 \\
\hline Relative risk of coronary event year $2+$ & 0.71 & $0.59-0.84$ & Lognormal & 4 \\
\hline Relative risk of revascularization year $2+$ & 0.73 & $0.59-0.9$ & Lognormal & 4 \\
\hline Relative risk of stroke year $2+$ & 0.79 & $0.57-1.1$ & Lognormal & 4 \\
\hline \multicolumn{5}{|l|}{ Cardiovascular event distribution } \\
\hline CHD death & 0.15 & $0.12-0.18$ & Dirichlet & 27 \\
\hline Myocardial infarction & 0.16 & $0.13-0.19$ & Dirichlet & 27 \\
\hline Angina & 0.38 & $0.30-0.46$ & Dirichlet & 27 \\
\hline Revascularization & 0.24 & $0.19-0.29$ & Dirichlet & 27 \\
\hline Stroke & 0.07 & $0.06-0.08$ & Dirichlet & 27 \\
\hline \multicolumn{5}{|l|}{ Adherence } \\
\hline Probability of non-persistence year I & 0.23 & $0.19-0.28$ & Beta & 6 \\
\hline Probability of non-persistence year 2 & 0.22 & $0.18-0.26$ & Beta & 6 \\
\hline Probability of non-persistence year 3 & 0.16 & $0.13-0.19$ & Beta & 6 \\
\hline Probability of non-compliance year I & 0.25 & $0.20-0.30$ & Beta & 6,30 \\
\hline Probability of non-compliance year 2 & 0.25 & $0.20-0.30$ & Beta & 6,30 \\
\hline Probability of non-compliance year 3 & 0.25 & $0.20-0.30$ & Beta & 6,30 \\
\hline Probability of becoming compliant following MI & 0.85 & $0.68-1.00$ & Beta & 10 \\
\hline $\begin{array}{l}\text { Probability of becoming compliant after CVD } \\
\text { hospitalization }\end{array}$ & 0.63 & $0.50-0.76$ & Beta & 10 \\
\hline Probability of physician visit & 0.70 & $0.56-0.84$ & Beta & 10 \\
\hline $\begin{array}{l}\text { Probability of becoming compliant following cardiolo- } \\
\text { gist visit }\end{array}$ & 0.74 & $0.59-0.89$ & Beta & 10 \\
\hline $\begin{array}{l}\text { Probability of becoming compliant following primary } \\
\text { care visit }\end{array}$ & 0.58 & $0.46-0.69$ & Beta & 10 \\
\hline \multicolumn{5}{|l|}{ Impact of adherence } \\
\hline $\begin{array}{l}\text { Relative risk of CVD event with non-compliance vs } \\
\text { compliance }\end{array}$ & 1.35 & $1.21-1.50$ & Lognormal & 15,19 \\
\hline $\begin{array}{l}\text { Relative risk of all-cause mortality with non-compliance } \\
\text { vs compliance }\end{array}$ & 1.85 & $1.63-2.09$ & Lognormal & 15,19 \\
\hline $\begin{array}{l}\text { Relative risk of CVD event with non-persistence vs } \\
\text { persistence }\end{array}$ & 1.35 & $|.21-1.5|$ & Lognormal & 15,28 \\
\hline $\begin{array}{l}\text { Relative risk of all-cause mortality with non-persistence } \\
\text { vs persistence }\end{array}$ & 2.78 & $1.96-3.72$ & Lognormal & 15,28 \\
\hline \multicolumn{5}{|l|}{ Health state utilities } \\
\hline Starting utility secondary prevention & 0.704 & $0.575-0.843$ & Beta & 31 \\
\hline Post-second CVD event & 0.581 & $0.452-0.720$ & Beta & 31 \\
\hline
\end{tabular}

largest overall effect on model results, while inputs related to risk of events and utlity values had a lesser impact.
Probabilistic sensitivity analysis used a Monte Carlo approach with 5,000 model simulations. The cost 
Table 2 Cost inputs

\begin{tabular}{|c|c|c|c|c|}
\hline Event (acute cost) & Value & Range & Distribution & Source \\
\hline Non-fatal MI & $\$ 39,981$ & $\$ 27,615-\$ 51,876$ & Gamma & 23 \\
\hline Fatal MI & $\$ 52,267$ & $\$ 21,402-\$ 59,943$ & Gamma & 23 \\
\hline Cardiac arrest & $\$ 45,204$ & $\$ 17,137-\$ 51,795$ & Gamma & 23 \\
\hline Stroke & $\$ 74,057$ & $\$ 58,494-\$ 94,048$ & Gamma & 23 \\
\hline $\mathrm{PCl}$ & $\$ 84,821$ & $\$ 69,927-\$ 113,597$ & Gamma & 23 \\
\hline CABG & $\$ 162,911$ & $\$ 120,669-\$ 268,096$ & Gamma & 23 \\
\hline Angina & $\$ 19,978$ & $\$ 19,973-\$ 19,982$ & Gamma & 23 \\
\hline Cardiologist office visit & $\$ 146$ & $\$ 113-\$ 160$ & Gamma & 36 \\
\hline Primary care office visit & $\$ 74$ & $\$ 52-\$ 81$ & Gamma & 36 \\
\hline \multicolumn{5}{|l|}{ States (annual cost) } \\
\hline Compliant with statins & $\$ 132$ & $\$ 106-\$ 158$ & Gamma & 37 \\
\hline Non-compliant with statins & $\$ 79$ & $\$ 63-\$ 95$ & Gamma & 37 \\
\hline Secondary prevention state & $\$ 7,700$ & $\$ 5,828-\$ 9,713$ & Gamma & 32,38 \\
\hline
\end{tabular}

effectiveness plane for the Electronic Pill Bottle intervention, which demonstrated the largest relative improvement in adherence, is shown in Figure 4. Additional cost effectiveness planes are shown in Figure S1. The QALY gain was small with $98 \%$ of simulations showing a QALY gain of less than 3 months. Incremental costs were less than $\$ 15,000$ in all simulations and less than $\$ 5,000$ in $76 \%$. Both Discharge Letter and Nurse/dietician Counselling had a 3\% probability of being cost saving while incremental costs for IVR+ $(96 \%)$ and Disease Management (96\%) were likely below \$5,000. The cost effectiveness acceptability curves for all interventions are shown in Figure 5. The analysis found the probability of the Electronic Pill Bottle intervention being cost effectiveness at the \$50,000/QALY threshold was 97\%. Additionally, Discharge Letter (98\%), IVR+ (93\%) and Nurse/dietician Counselling (81\%) were likely to be cost effective.

\section{Discussion}

This literature review identified six interventions which demonstrated a statistically significant improvement in adherence, including 1 disease management program, 2 with follow-up counselling, 1 with increased information at discharge, and 2 reminder interventions. ${ }^{40,43,45,47-50}$ From most to least cost effective the interventions were: Discharge Letter, Electronic Pill Bottle, IVR+, Nurse/ Dietician Counseling, Nurse Counseling and Disease Management. Economic analysis suggests a strong relationship between effectiveness and costs. Interventions achieving only a small improvement in adherence must be low cost, less than $\$ 100-\$ 200$ per patient per year, in order to be cost effective. Interventions that double adherence could cost up to $\$ 1,000$ per year and remain cost effective.

There was a great deal of heterogeneity in the design of the interventions, the methods to assess adherence, the definition of adherence (compliance vs persistence) and the duration of the interventions. Only 1 study considered the costs of the intervention itself. Studies that occur within 12 months are too short for health care decision makers to understand the long-term benefits for chronic diseases while those that do not contain economic evaluations prevent decision makers from estimating the value for money.

Two previous systematic reviews assessing the effectiveness of interventions to improve adherence to statins have been completed. Van Driel and colleagues conducted a systematic review of randomized controlled trials of adherence interventions for the Cochrane collaboration in 2016 which included 35 studies. ${ }^{51}$ Their analysis found that interventions classified as "intensification of care", which included reminders, pharmacist support and physician education efforts demonstrated better adherence and better lipid management over the short and long term compared to usual care. Other intervention types, such as complex behavioral approaches, administrative support and regimen simplification did not consistently improve adherence. This review found interventions which could be classified as intensification of care similarly improved adherence, including reminders through electronic pill bottle or IVR and nurse/dietician counselling.

A narrative synthesis of adherence intervention was developed by Jornten-Karlsson et al. ${ }^{52}$ They identified 32 


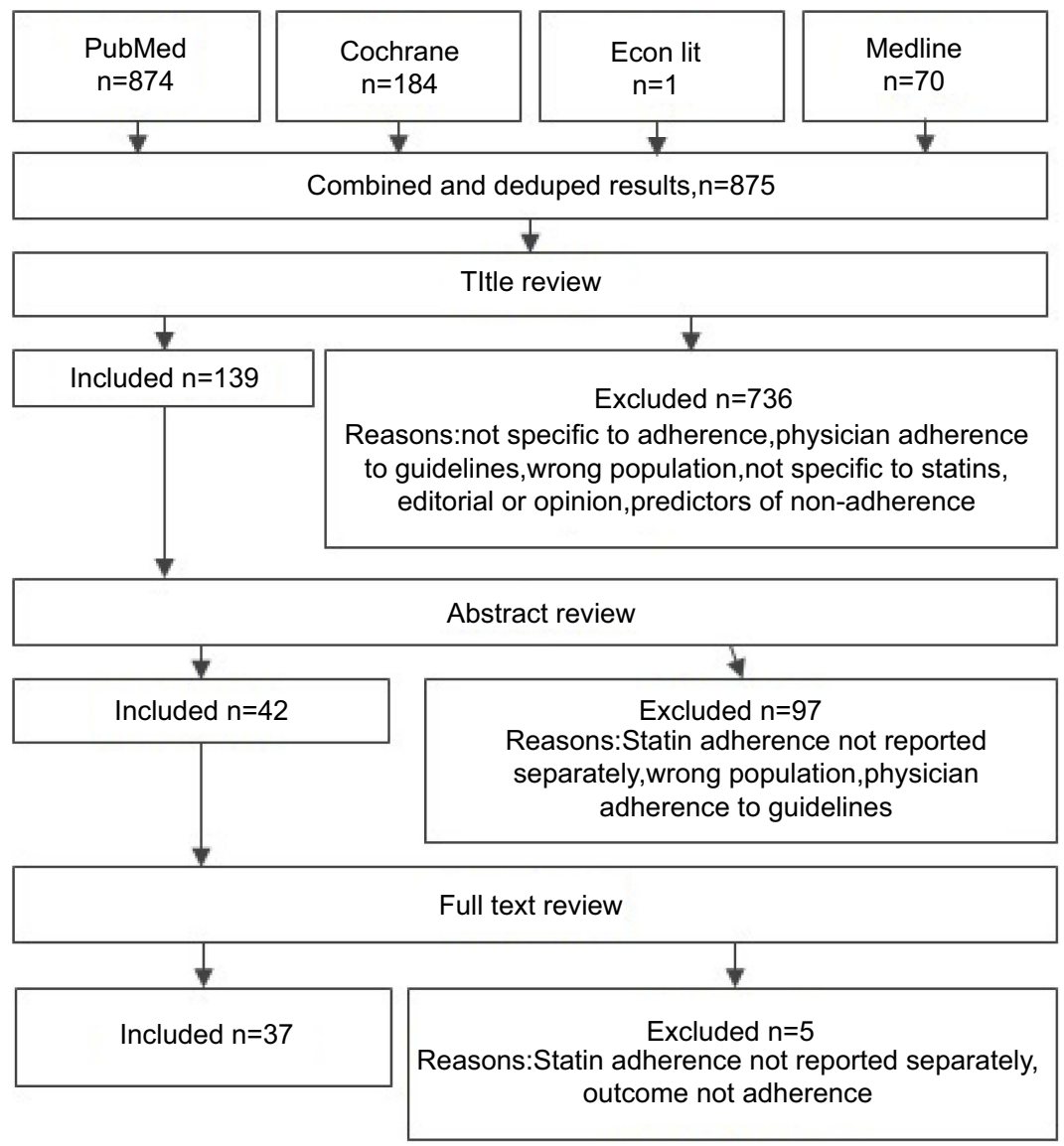

Figure 2 Diagram of searches and study inclusion selection.

controlled studies of patient-centered interventions and found that behavioral counselling, delivered several times face-to-face, consistently improved adherence. They found interventions using medication reminders or feedback alone did not improve adherence. Likewise, this review found repeated counseling had a positive impact on adherence. However, it also identified two reminder interventions which did demonstrate improvement in adherence, at least over the shorter term of 3-12 months. It should be noted that interventions based on repeated contact with a health professional tend to be more expensive than more automated approaches and therefore should demonstrate a large adherence improvement in order to be considered good value for money.

Importantly, there have also been two studies which evaluated the economics of interventions to improve statin adherence. The study by Vollmer et al included in this analysis subsequently underwent an economic evaluation. ${ }^{53}$ They assessed cost effectiveness based on willingngess to pay for a unit increase in adherence or a unit decrease in LDL-C and found extended dominance for IVR+ with an ICER of \$28.77.
The ICER decreased to $\$ 16.90$ in the sub-group with baseline adherence $<50 \%$ and decreased further to $\$ 12.13$ in the subgroup with baseline LDL-C $>100 \mathrm{mg} / \mathrm{dL}$. The probability of cost effectiveness was $>80 \%$ in this population at a willingness to pay of $\$ 55$. They note that whilst more resource intensive interventions appear to be lower value for money, in the case of statins, they deliver better value in terms of outcomes. While this analysis used a different methodology to assess cost effectiveness as incremental cost per quality-adjusted life year gained, it similarly found that the IVR+ intervention was likely to be cost effective. Vegter and colleagues conducted a cost effectiveness analysis of a pharmacist led intervention to reduce discontinuation of statin therapy. ${ }^{54}$ The intervention involved continuous medication monitoring in 9 community pharmacies in the Netherlands for new statin users. The effectiveness of the intervention had been previously published and had cut discontinuation approximately in half. ${ }^{55}$ Cost of the intervention was taken directly from the intervention study and found to be $€ 36.80$ ( $\$ 46.80$ ) per patient selected for intervention. Results found that drug and disease management costs were increased by $€ 114$ (\$145) over 5 years. However, these 


\begin{tabular}{|c|c|c|c|c|c|c|}
\hline 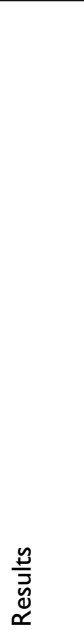 & 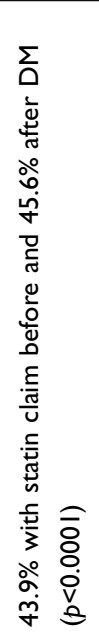 & 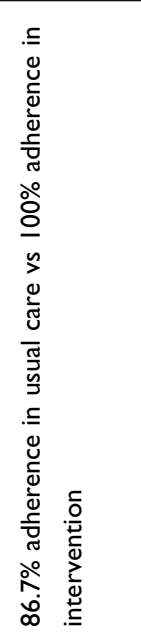 & 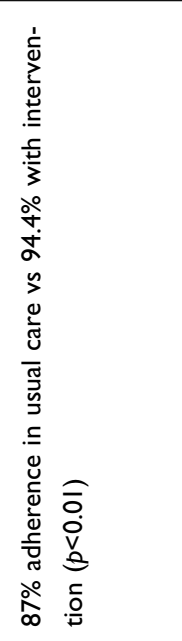 & 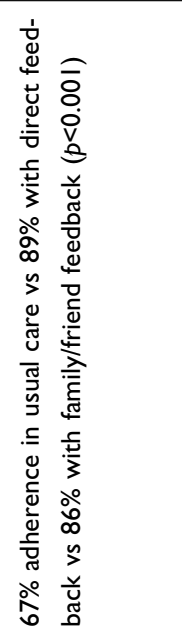 & 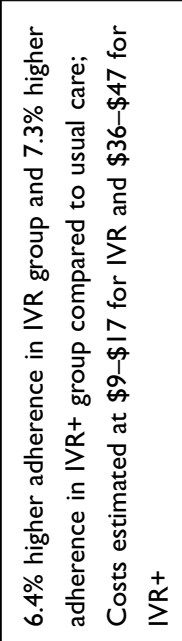 & 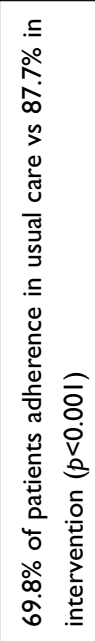 \\
\hline 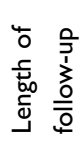 & 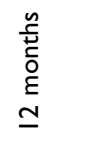 & 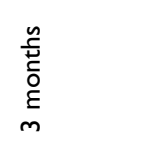 & 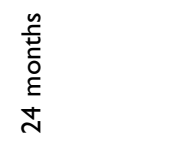 & 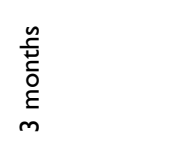 & 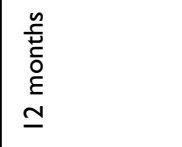 & 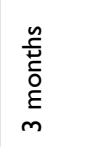 \\
\hline 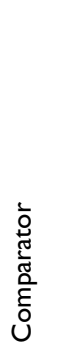 & 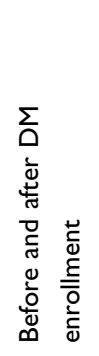 & 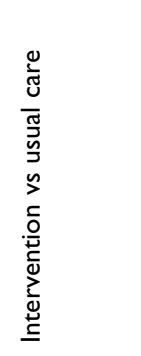 & 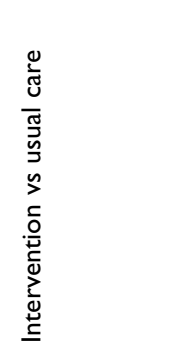 & 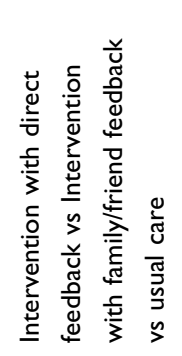 & 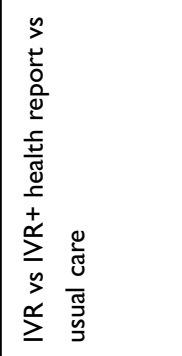 & 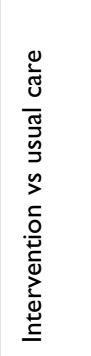 \\
\hline $\begin{array}{l}\frac{0}{0} \\
\frac{0}{0} \\
\frac{0}{0} \\
0\end{array}$ & 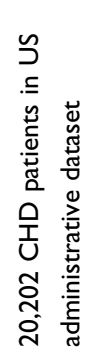 & 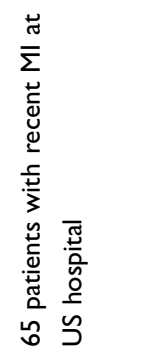 & 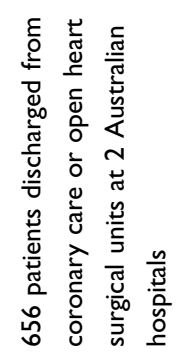 & 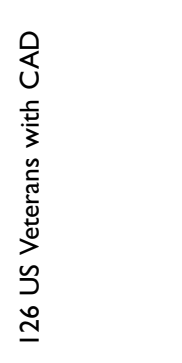 & 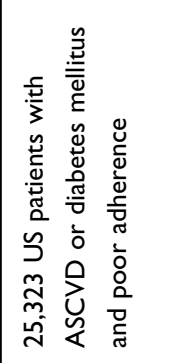 & 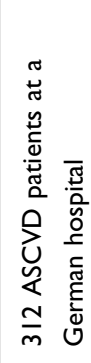 \\
\hline 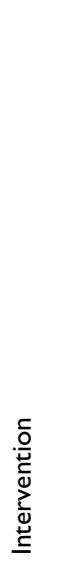 & 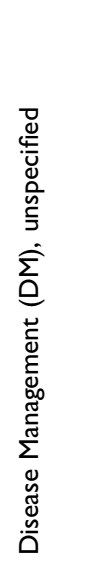 & 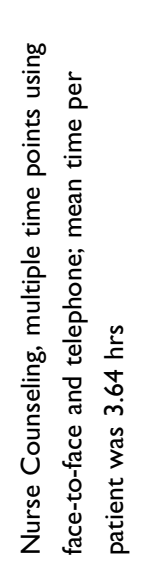 & 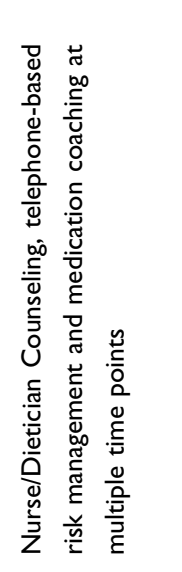 & 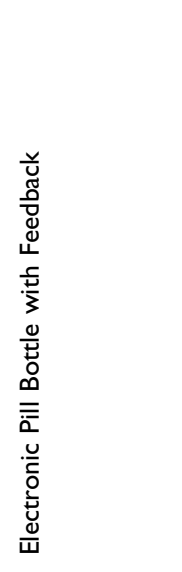 & 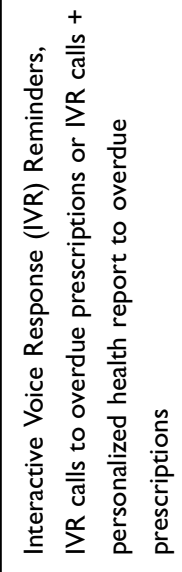 & 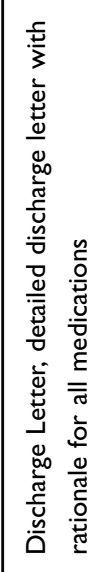 \\
\hline 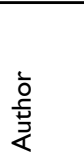 & 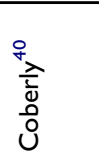 & 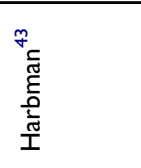 & 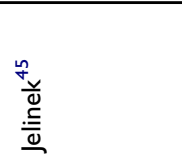 & 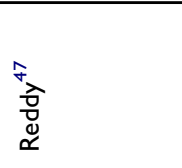 & 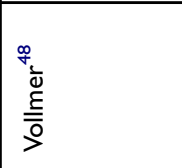 & 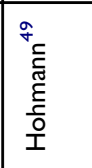 \\
\hline
\end{tabular}


Table 4 Economic results

\begin{tabular}{|c|c|c|c|c|c|}
\hline Intervention & $\begin{array}{l}\text { Relative } \\
\text { Improvement }\end{array}$ & Estimate Cost & $\begin{array}{l}\text { Incremental Costs } \\
\text { per patient }\end{array}$ & $\begin{array}{l}\text { Incremental QALYs } \\
\text { per patient }\end{array}$ & ICER \\
\hline Disease Management ${ }^{40}$ & 1.04 & $\$ 261.57$ per patient annually & $\$ 2,424$ & 0.02 & $\$ 130,399$ \\
\hline $\begin{array}{l}\text { Nurse Counselling for } 3.64 \text { hrs } \\
\text { every } 3 \text { mos. }^{43}\end{array}$ & 1.15 & $\$ 745.37$ per patient annually & $\$ 7,320$ & 0.07 & $\$ 111,173$ \\
\hline Discharge Letter ${ }^{49}$ & 1.26 & $\$ 51.19$ once & $\$ 2,950$ & 0.11 & $\$ 27,545$ \\
\hline Nurse/dietician Counselling ${ }^{45}$ & 1.11 & $\$ 65.40$ per patient annually & $\$ 1,808$ & 0.05 & $\$ 36,463$ \\
\hline $\begin{array}{l}\text { Electronic pill bottle }+ \\
\text { feedback }^{47}\end{array}$ & 1.33 & $\begin{array}{l}\$ 28.96 \text { once for pill bottle }+\$ 40.86 \\
\text { per patient annually }\end{array}$ & $\$ 3,900$ & 0.13 & $\$ 29,631$ \\
\hline $\mathrm{IVR}+{ }^{48}$ & 1.16 & $\$ 49.52$ per patient annually & $\$ 2,169$ & 0.07 & $\$ 32,357$ \\
\hline
\end{tabular}

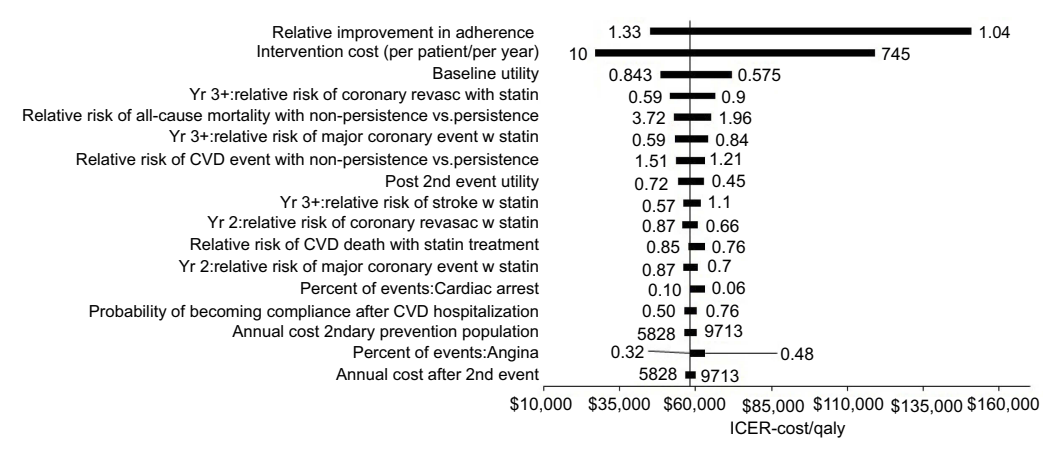

Figure 3 One-way sensitivity analysis.

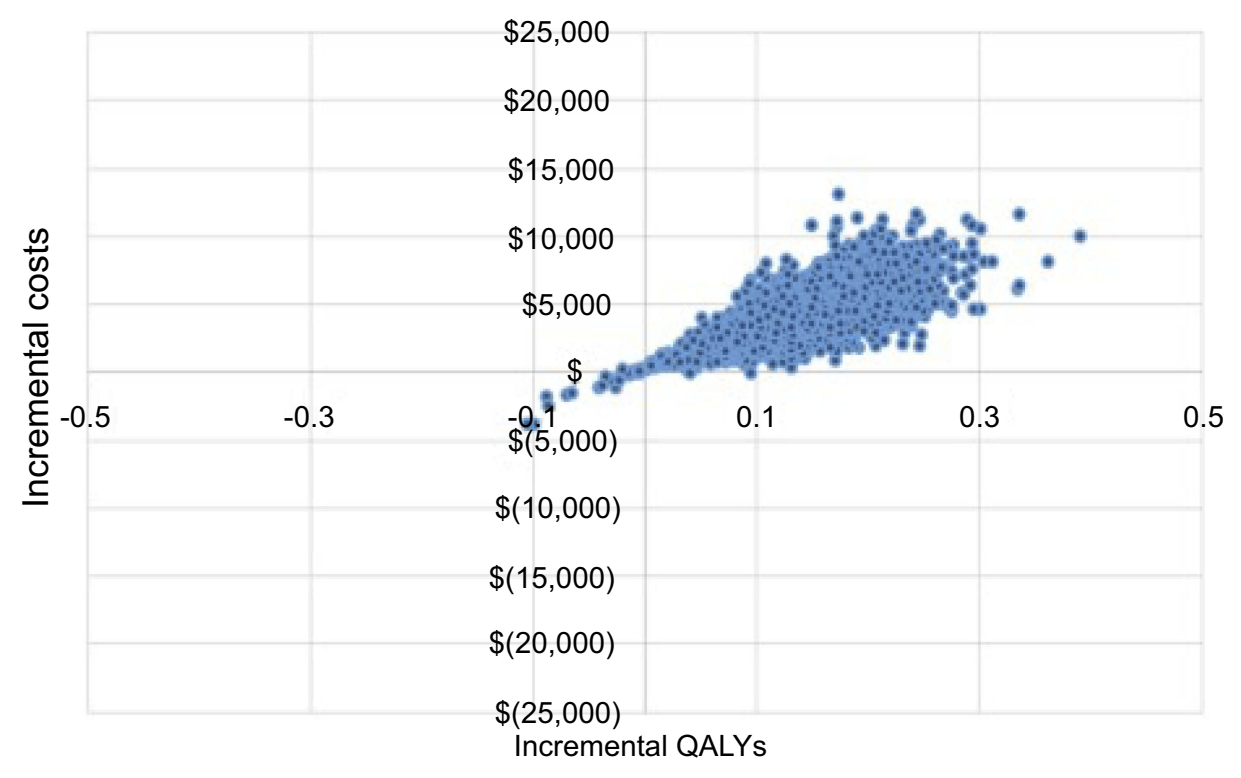

Figure 4 Cost effectiveness plane for electronic pill bottle intervention. 


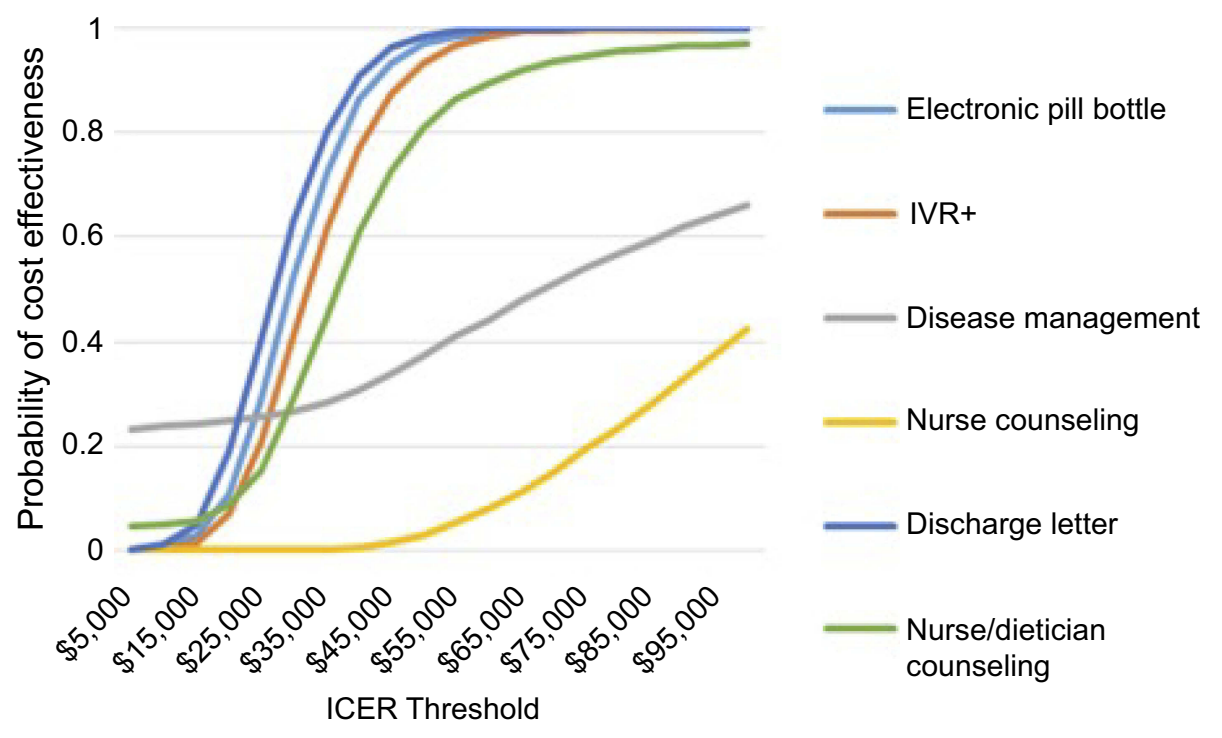

Figure 5 Cost effectiveness acceptability curves for interventions.

costs as well as cost of the intervention were offset and thus generated a savings of $€ 126(\$ 160)$ per patient over 5 years.

There were some differences between Vegter's analysis and this one. While this cost effectiveness analysis allowed for adherence, non-compliance or non-persistence, Vegter and colleagues allowed for only persistence or non-persistence. Nor did they allow for the possibility of resumption of statin therapy outside of the intervention, while this analysis allowed that patients may resume therapy due to usual care.

A key strength of this analysis is in adding information on the costs and cost effectiveness of interventions to improve statin adherence to the body of evidence describing only effectiveness. A strength of the economic analysis is the attention paid to the temporal nature of statin taking, specifically that the benefit in terms of risk reduction accrues with time on treatment. This economic analysis also considers both non-persistence and non-compliance, thus capturing and differentiating the impact of each nonadherence behaviour.

\section{Limitations}

However, there are also several limitations to consider. The time period of the literature review was 2006 to 2016, which almost certainly excluded several interventions published before that time. It also purposely excluded interventions focused on the polypill or patient co-pays which eliminated other methods of improving adherence. Further, the literature search excluded literature on predictors of non-adherence to statins. The ability to better target adherence interventions through identification of those most likely to be non-adherent would certainly improve the cost effectiveness of any intervention.

This model assumed that the benefits of statin taking ceased when medication is stopped, which is in line with literature describing the impact of non-adherence. However, other studies have shown that statin therapy confers some benefits, even after therapy has been stopped, although the exact level of benefit is unknown. ${ }^{56}$ This analysis did not use a lower utility to reflect the impact of side effects from statin taking which may overestimate the QALYs associated with being on statin therapy.

An important consideration in any study of adherence is the "healthy adherer" effect whereby those most likely to be adherent are also those most likely to adopt other healthy habits and therefore achieve better outcomes. This possibility confounds any observational research on adherence and outcomes. Only 1 study included directly addressed this by comparing the impact of adherence to statins vs aspirin. ${ }^{14}$

Lastly, this economic analysis assumed that the intervention would continue for a patient's lifetime, while the interventions in the literature were limited to 1 year or less. It is unknown if these interventions would continue to be effective over this longer time horizon.

\section{Implications for policy makers}

Findings of this literature review and economic analysis indicate that interventions to improve statin adherence 
may be cost effective, depending on the level of effectiveness and total costs of the intervention. The modest adherence improvement demonstrated in the literature suggests that interventions should strive towards minimal costs in order to be cost effective. Efforts should thus be made to identify low cost methods to improve adherence to statins, which may include education and communication to reduce the asymmetry of information between doctor and patient and ensure that doctor and patient are in agreement on the need for the medication.

\section{Further research needed}

Use of adherence measures vary and terminology around adherence is inconsistent. Measures such as Medication Possession Ratio or Proportion of Days Covered obfuscate the details around adherence, making it difficult to understand if the issue is therapy discontinuation or irregular medication taking. Future research should distinguish between those who discontinue therapy for a period of time and those who skip doses occasionally, as those behaviors indicate different issues with medication taking and thus will likely require different interventions to effectively address.

Lastly, only the study of IVR + considered costs, and two other studies quantified the amount of time required for the intervention. This analysis finds that the cost effectiveness of any adherence intervention is sensitive to the intervention costs. Therefore, future studies on adherence interventions should consider at least the resources required to implement, if not undertaking a more thorough cost analysis.

\section{Conclusion}

This analysis found that most interventions to improve adherence to statin therapy in the secondary prevention population produced small or no improvements in adherence. Nonetheless, these small gains can be important at a population level, and several of these interventions were found to be cost effective, despite the small improvement. Interventions which can produce improvements in adherence while also being low cost are most likely to be cost effective and are urgently needed in order to reduce the burden of ASCVD.

\section{Acknowledgments}

This manuscript was developed from research undertaken as part of a Masters of Science degree with the London School of Hygiene and Tropical Medicine. The Medicines Company provided funding for the journal submission fees.

\section{Disclosure}

Ms. Shannon Armstrong is an employee and shareholder of the Medicines Company. The authors report no other conflicts of interest in this work.

\section{References}

1. Khavjou O, Phelps D, Leib A. Cardiovascular disease burden: a costly burden for America. Am Heart Assoc. 2016.

2. Centers for Disease Control and Prevention. Heart Disease Facts. https:// www.cdc.gov/heartdisease/facts.htm. Accessed October 3, 2016.

3. Centers for Disease Control and Prevention. High Cholesterol in the United States. http://www.cdc.gov/cholesterol/facts.htm. Accessed October 3, 2016.

4. Baigent C, Keech A, Kearney PM, et al.; Cholesterol Treatment Trialists (CCT) Collaborators. Efficacy and safety of cholesterol-lowering treatment: prospective meta-analysis of data from 90,056 participants in 14 randomised trials of statins. Lancet. 2005;366:12671278. doi:10.1016/S0140-6736(05)67394-1

5. Consumer Reports. Best Buy Drugs: Evaluating Statin Drugs to Treat High Cholesterol and Heart Disease. New York, NY: Consumer Reports;2014.

6. Lin I, Sung J, Sanchez RJ, et al. Patterns of statin use in a real-world population of patients at high cardiovascular risk. J Manag Care Spec Pharm. 2016;22(6):685-698. doi:10.18553/jmcp.2016.22.6.685

7. Newby LK, Lapoint NMA, Chen AY, et al. Long-term adherence to evidence based secondary prevention therapies in coronary artery disease. Circulation. 2006;113:203-212. doi:10.1161/ CIRCULATIONAHA.105.505636

8. Choudhry NK, Setoguchi S, Levin R, Winkelmayer WC, Schrank W. Trends in adherence to secondary prevention medications in elderly post-myocardial infarction patients. Pharmacoepidemiol Drug Saf. 2008;17(12):1189-1196. doi:10.1002/pds.1671

9. Lemstra M, Blackburn D. Nonadherence to statin therapy: discontinuation after a single fill. Can J Cardiol. 2012;28:567-573. doi:10.1016/j.cjca.2012.03.018

10. Brookheart AM, Patrick AR, Schneeweiss S, et al. Physician follow-up and provider continuity are associated with long-term medication adherence. Arch Intern Med. 2007;167:847-852. doi:10.1001/archinte.167.8.847

11. Pittman DG, Chen W, Bowlin SJ, Foody JM. Adherence to statins, subsequent healthcare costs, and cardiovascular hospitalizations. Am J Cardiol. 2011;107(11):1662-1666. doi:10.1016/j. amjcard.2011.01.052

12. Bijlsma M, Vansteelandt S, Janssen F, Hak E. The effect of adherence to statin therapy on cardiovascular mortality: quantification of unmeasured bias using falsification end-points. BMC Public Health. 2016;16:303. doi:10.1186/s12889-016-2986-0

13. Haukka J, Niskanen L, Partonen T, Lonnqvist J, Tiihonen J. Statin usage and all-cause and disease-specific mortality in a nationwide study. Pharmacoepidemiol Drug Saf. 2012;21:61-69. doi:10.1002/ pds. 2255

14. Wei L, Fahey T, MacDonald TM. Adherence to statin or aspirin or both in patients with established cardiovascular disease: exploring healthy behavior vs. drug effects and 10-year follow-up of outcome. Br J Clin Pharmacol. 2008;66(1):110-116. doi:10.1111/j.13652125.2008.03212.x

15. De Vera M, Bhole V, Burns LC, Lacaille D. Impact of statin adherence on cardiovascular disease and mortality outcomes: a systematic review. Br J Clin Pharmacol. 2014;78(4):684-698. doi:10.1111/bcp.12339

16. Hamood H, Hamood R, Green MS, Almog R. Effect of adherence to evidence-based therapy after acute myocardial infarction on all-cause mortality. Pharmacoepidemiol Drug Saf. 2015;24:1093-1104. doi:10.1002/pds.3840 
17. Chen PS, Cheng CL, Yang YH, Li YH. Statin adherence after ischemic stroke or transient ischemic attack is associated with clinical outcome. Circ J. 2016;80:731-737. doi:10.1253/circj.CJ-15-0753

18. Herttua K, Martikainen P, Batty GD, Kivimaki M. Poor adherence to statin and antihypertensive therapies as risk factors for fatal stroke. $J \mathrm{Am}$ Coll Cardiol. 2016;67(13):1507-1515. doi:10.1016/j.jacc.2016.01.044

19. Ho PM, Magid DJ, Shetterly SM, et al. Medication non-adherence is associated with a broad range of adverse outcomes in patients with coronary artery disease. Am Heart J. 2008;155:772-779. doi:10.1016/j.ahj.2007.12.011

20. Rasmussen JN, Chong A, Alter DA. Relationship between adherence to evidence-based pharmacotherapy and long-term mortality after acute myocardial infarction. JAMA. 2007;297:177-186. doi:10.1001/jama.297.2.177

21. Poluzzi E, Piccinni C, Carta P, et al. Cardiovascular events in statin recipients: impact of adherenc to treatment in a 3-year record linkage study. Eur J Clin Pharmacol. 2011;67:407-414. doi:10.1007/s00228010-0958-3

22. Siebert W, Alagoz O, Bayloumi AM, et al. State-transition modelling: a report of the ISPOR-SMDM modelling good research practices task force-3. Value Health. 2012;15:812-820. doi:10.1016/j.jval.2012.06.014

23. National Inpatient Sample 2014. Healthcare cost and utilization project. https://hcupnet-archive.ahrq.gov/. Accessed May 12, 2017.

24. D'Agostino RB, Russell MW, Huse DM, et al. Primary and subsequent coronary risk appraisal: new results from the Framingham Study. Am Heart J. 2000;139(2):272-281. doi:10.1067/mhj.2000.96469

25. Hankey GJ, Jamrozik K, Broadhurst RJ, et al. Long-term risk of first recurrent stroke in the Perth community stroke study. Stroke. 1998;29:2491-2500.

26. Heart Protection Study Collaborative Group. Effects of cholesterol-lowering with simvastatin on stroke and other major vascular events in 20 536 people with cerebrovascular disease or other high-risk condition. Lancet. 2004;363:757-767. doi:10.1016/S0140-6736(04)15690-0

27. The Long-term Intervention with Pravastatin in ischaemic disease (LIPID) Study Group. Prevention of cardiovascular events and death with pravastatin in patients with coronary heart disease and a broad range of initial cholesterol levels. $N$ Engl J Med. 1998;339 (19):1349-1357. doi:10.1056/NEJM199811053391902

28. Rublee DA, Chen SY, Mardekian J, Wu N, Rao P, Boulanger L. Evaluation of cardiovascular morbidity associated with adherence to atorvastatin therapy. Am J Ther. 2012;19:24-32. doi:10.1097/ MJT.0b013e3181ee707e

29. Arias E, Heron M, Xu J. National vital statistics reports, United States life tables 2012. Natl Health Stat. 2016;65(8):1-65.

30. Vupputuri S, Joski P, Kilpatrick R, et al. LDL cholesterol response and statin adherence among high-risk patients initiating treatment. Am J Manag Care. 2016;22(3):e106-e115.

31. Sullivan PW, Ghushchyan V. Preference-based EQ-5D index scores for chronic conditions in the United States. Med Decis Making. 2006;26(4):410-420. doi:10.1177/0272989X06290495

32. Arrieta A, Page TF, Veledar E, Nasir K. Economic evaluation of PCSK9 inhibitors in reducing cardiovascular risk from health system and private payer perspectives. PLOSone. 2017;12:e169761. doi:10.1371/journal.pone.0169761

33. Shiffman, D, Arellano AR, Caulfield MP, et al. Use of low density lipoprotein particle number levels as an aid in statin treatment decisions for intermediate risk patients: a cost effectiveness analysis. $B M C$ Cardiovasc Disord. 2016;16:251. doi:10.1186/s12872-016-0371-7

34. National Inpatient Sample 2014. Healthcare cost and utilization project. https://hcupnet-archive.ahrq.gov/. Accessed March 30, 2017.

35. Chapman RH, Ferrufino CP, Kowal SL, Classi P, Roberts CS. The costs and effectiveness of adherence-improving interventions for antihypertensive and lipid-lowering drugs. Int J Clin Pract. 2010;64 (2):169-181. doi:10.1111/j.1742-1241.2009.02196.x
36. Centers for Medicare \& Medicaid Services. Current procedure terminology, physician fee schedule. https://www.cms.gov/apps/physicianfee-schedule/license-agreement.aspx, Accessed July 17, 2017.

37. Medi-Span Price Rx Database. http://www.wolterskluwercdi.com/ price-rx/. Accessed May 12, 2017.

38. Erickson KF, Japa S, Owens DK, et al. Cost-effectiveness of statins for primary cardiovascular prevention in chronic kidney disease. J Am Coll Cardiol. 2013;61(12):1250-1258. doi:10.1016/ j.jacc.2012.12.034

39. Siegel JE, Torrance GW, Russell LB, Luce BR, Weinstein MC, Gold MR. Guidelines for pharmacoeconomic studies. Recommendations from the panel on cost effectiveness in health and medicine. Panel on cost effectiveness in health and medicine. Pharmacoeconomics. 1997;11(2):159-168. doi:10.2165/00019053199711020-00005

40. Coberly C, Morrow G, McGinnis M, et al. Increased adherence to cardiac standards of care during participation in cardiac disease management programs. Dis Manage. 2008;11(2):111-118. doi:10.1089/dis.2008.112725

41. Calvert SB, Kramer JM, Anstrom KJ, Kaltenbach LA, Stafford JA, LaPoint NM. Patient-focused intervention to improve longterm adherence to evidence-based medications: a randomised trial. Am Heart J. 2012;163(657-665.e1). doi:10.1016/j. ahj.2012.02.010

42. Damush TM, Myers L, Anderson JA, et al. The effect of a locally adapted, secondary stroke risk factor self-management program on medication adherence among veterans with stroke/TIA. Transl Behav Med. 2016;6:457-468.

43. Harbman P. The development and testing of a nurse practitioner secondary prevention intervention for patients after acute myocardial infarction: a prospective cohort study. Int J Nurs Stud. 2014;51:15421568. doi:10.1016/j.ijnurstu.2014.04.004

44. Ma Y, Ockene IS, Rosal MC, Merriam PA, Ockene JK, Gandhi PJ. Randomised trial of a pharmacist-delivered intervention for improving lipid-lowering medication adherence among patients with coronary heart disease. Cholesterol. 2010;383281. doi:10.1155/2010/ 383281

45. Jelinek M, Vale MJ, Liew D, et al. The $\mathrm{COACH}$ program produces sustained improvements in cardiovascular risk factors and adherence to recommended medications - two years follow-up. Heart Lung Circ. 2009;18:388-392. doi:10.1016/j.hlc.2009.06.001

46. Park LG, Howie-Esquivel J, Chung ML, Dracup K. The test messaging intervention to promote medication adherence for patients with coronary heart disease: a randomised controlled trial. Patient Educ Couns. 2014;94:261-268. doi:10.1016/j.pec.2013.10.027

47. Reddy A, Huseman TL, Canamucio A. Patient and partner feedback reports to improve statin medication adherence: a randomised control trial. J Gen Intern Med. 2016;32(3):256-261. doi:10.1007/s11606016-3858-0

48. Vollmer WM, Owen-Smith AA, Tom JO. Improving adherence to cardiovascular disease medications with information technology. $\mathrm{Am}$ J Manag Care. 2014;20(11):SP502-SP510.

49. Hohmann C, Neumann-Haefelin T, Klotz JM, Freidank A, Radziwill $\mathrm{R}$. Providing systematic detailed information on medication upon hospital discharge as an important step towards improved transitional care. J Clin Ther. 2014;39:286-291.

50. Hohmann C, Neumann-Haefelin T, Klotz JM, Freidank A, Radziwill $\mathrm{R}$. Adherence to hospital discharge medication in patients with ischemic stroke: a prospective, interventional 2-phase study. Stroke. 2013;44:522-524. doi:10.1161/STROKEAHA.112.678847

51. Van Driel ML, Morledge MD, Ulep R, Shaffer JP, Davies P, Deichmann R. Interventions to improve adherence to lipid-lowering medication (Review). Cochrane Database Syst Rev. 2016;12. doi:10.1002/14651858.CD003091.pub4 
52. Jörntèn-Karlsson M, Pintat S, Molloy-Bland M, Berg S, Ahlqvist M. Patient-centered interventions to improve adherence to statins: a narrative synthesis of systematically identified studies. Drugs. 2016;76:1447-1465. doi:10.1007/s40265-016-0640-x

53. Smith DH, O'Keefe-Rosetti M, Owen-Smith AA, et al. Improving adherence to cardiovascular therapies: an economic evaluation of a randomized pragmatic trial. Value Health. 2016;19(2):176-184. doi:10.1016/j.jval.2015.11.013

54. Vegter S, Oosterhof P, van Boven JFM, Stuurman-Bieze AGG, Hiddink EG, Postma MJ. Improving adherence to lipid-lowering therapy in a community pharmacy intervention program: a costeffectiveness analysis. J Manag Care Pharm. 2014;20(7):722-732.
55. Stuurman-Bieze AG, Hiddink EG, van Boven JF, Vegter S. Proactive pharmaceutical care interventions improve patients' adherence to lipid lowering medication. Ann Pharmacother. 2013;47(11):14481456. doi:10.1177/1060028013501146

56. Ford I, Murray H, McCowan C, Packard CJ. Long-term safety and efficacy of lowering low-density lipoprotein cholesterol with statin therapy: 20-year follow-up of West of Scotland Coronary Prevention Study. Circulation. 2016;133(11):1073-1080. doi:10.1161/ CIRCULATIONAHA.115.019014 


\section{Supplementary materials}

Table SI Search terms for structured literature review

\begin{tabular}{|l|l|l|}
\hline $\begin{array}{l}\text { Search categories } \\
\text { (connected with } \\
\text { Boolean AND) }\end{array}$ & List of Terms (connected with Boolean OR) & List of Subject Headings \\
\hline Statin & $\begin{array}{l}\text { Statin OR lipid lowering therapy OR lipid lowering treatment OR HMG- } \\
\text { CoA reductase inhibitor }\end{array}$ & $\begin{array}{l}\text { Hydroxymethylglutaryl-CoA } \\
\text { Reductase Inhibitors/ }\end{array}$ \\
\hline Secondary Prevention & $\begin{array}{l}\text { Cardiovascular disease OR } \\
\text { CVD OR } \\
\text { coronary artery disease OR coronary heart disease OR myocardial infarct* } \\
\text { OR } \\
\text { heart* OR } \\
\text { cerebrovascular accident OR } \\
\text { stroke* OR } \\
\text { vascular disease }\end{array}$ & $\begin{array}{l}\text { Cardiovascular diseases/ or exp heart } \\
\text { or exp vascular diseases/ }\end{array}$ \\
\hline Adherence & $\begin{array}{l}\text { Adherence OR compliance OR persistence } \\
\text { Cost* OR cost effectiveness OR cost utility analysis OR cost benefit analysis } \\
\text { OR cea OR cua OR cba OR economic* OR economic evaluation }\end{array}$ & Costs and cost analysis/ \\
\hline
\end{tabular}

Table S2 Inclusion/Exclusion criteria for literature review

\begin{tabular}{|l|l|}
\hline Population & Patients with ASCVD \\
\hline Intervention & $\begin{array}{l}\text { Interventions included anything focused on improving patient adherence to statin therapy, including patient education, provider } \\
\text { education, and prescription remainders. } \\
\text { The review excluded interventions focused only changing patient costs for medication, new pill formulations and interventions } \\
\text { focused on medications other than statins. }\end{array}$ \\
\hline Comparator & $\begin{array}{l}\text { Comparison groups included either a control arm of patients not receiving the intervention, or a historic control group of the } \\
\text { patients receiving the intervention in the period before the intervention. }\end{array}$ \\
\hline Outcomes & $\begin{array}{l}\text { The primary outcome measured was change in medication adherence which may be defined as compliance, persistence or both, } \\
\text { measured as proportion of days covered (PDC) or medication possession ratio (MPR), percent discontinuing treatment, time to } \\
\text { discontinuation, or other methods. Secondary outcomes included impact of adherence on outcomes, either LDL-C level or } \\
\text { second CVD event, as well as the cost of the intervention. }\end{array}$ \\
\hline
\end{tabular}


A

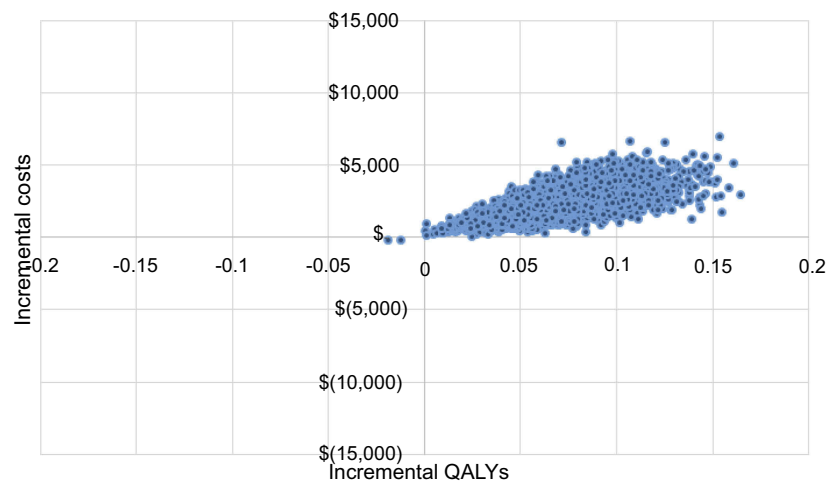

C

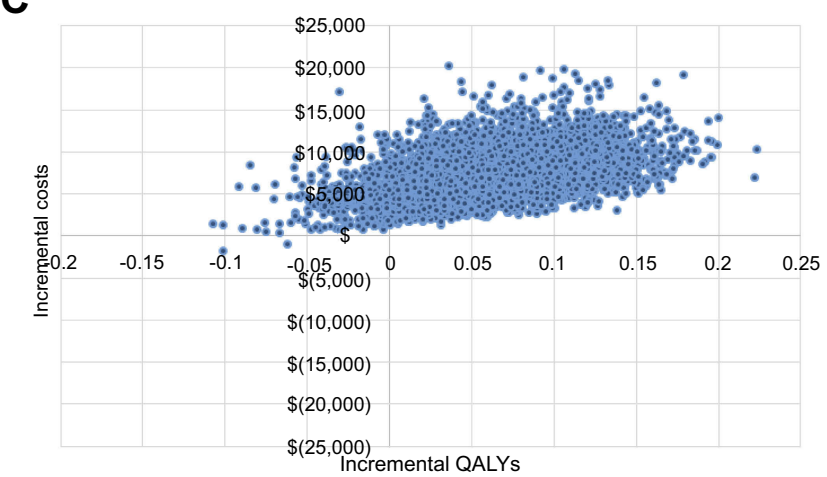

B

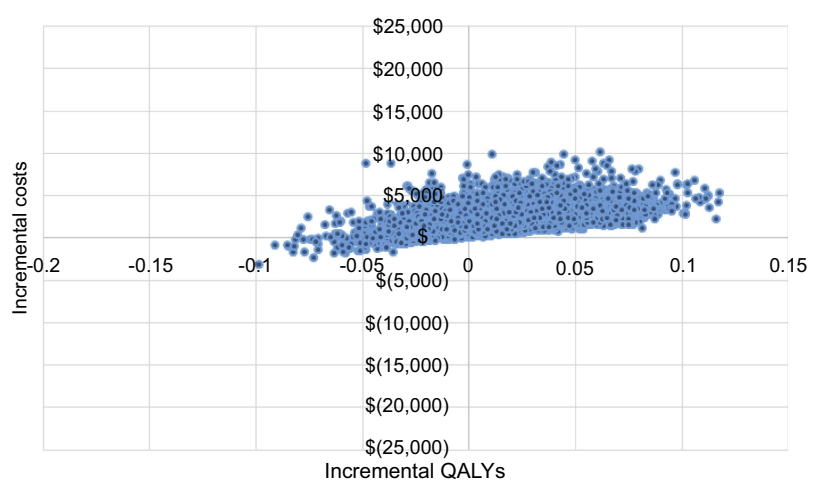

D

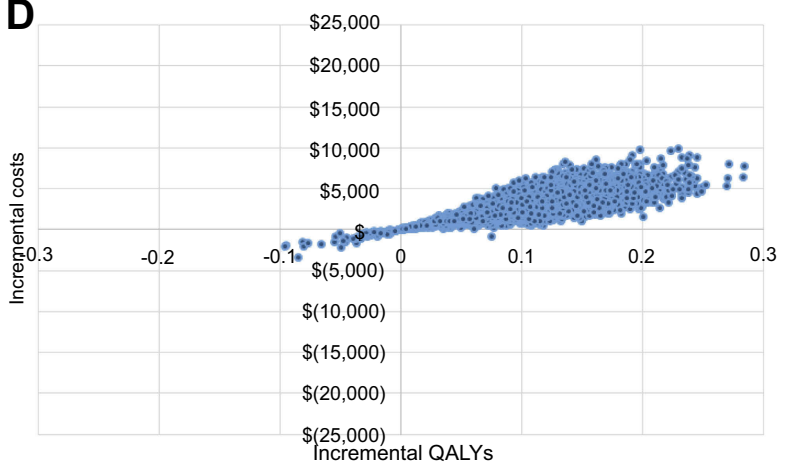

E

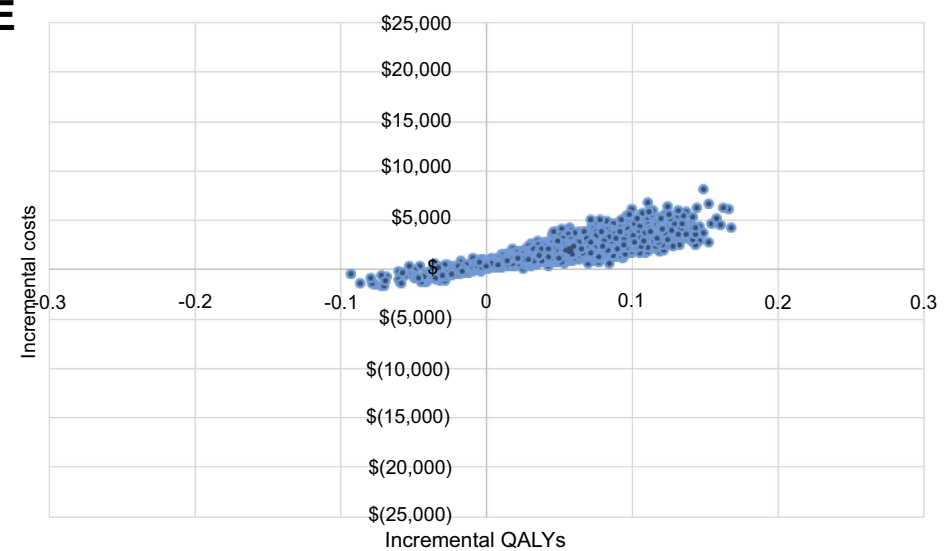

Figure SI (A) Cost effectiveness plane IVR intervention. (B) Cost effectiveness plan of Disease Management intervention. (C) Cost effectiveness plane of Nurse Counseling intervention. (D) Cost effectiveness plane of Discharge Letter intervention. (E) Cost effectiveness plane of Nurse/Dietician Counseling intervention.

\section{Publish your work in this journal}

Patient Preference and Adherence is an international, peer-reviewed, open access journal that focusing on the growing importance of patient preference and adherence throughout the therapeutic continuum. Patient satisfaction, acceptability, quality of life, compliance, persistence and their role in developing new therapeutic modalities and compounds to optimize clinical outcomes for existing disease states are major areas of interest for the journal. This journal has been accepted for indexing on PubMed Central. The manuscript management system is completely online and includes a very quick and fair peer-review system, which is all easy to use. Visit http:// www.dovepress.com/testimonials.php to read real quotes from published authors. 